\title{
Article
}

\section{Differences and Correlation Analysis of Birth Weight and Overweight/Obesity in Shanghai Twin Cohort}

\author{
Ping Liao ${ }^{1}$, Wen-Jing Wang ${ }^{1}$, Hui-Ting Yu ${ }^{1}$, Jia-Jie Zang ${ }^{1}$, Nai-Si Qian ${ }^{1}$, Xin He ${ }^{1}$, Wen-Jing Gao ${ }^{2}$, Can-Qing Yu², \\ Li-Ming $\mathrm{Li}^{2}$ and Fan Wu ${ }^{1,3}$ \\ ${ }^{1}$ Department of Functional Medicine, Department of Non-Communicable Diseases and Injuries, Shanghai Municipal Center for Disease Control and Prevention/ \\ Shanghai Institutes of Preventive Medicine, Shanghai, China, ${ }^{2}$ Department of Epidemiology and Biostatistics, School of Public Health, Peking University, Beijing, \\ China and ${ }^{3}$ Shanghai Medical College of Fudan University, Shanghai, China
}

\begin{abstract}
The objective of this study was to analyze differences in birth weight and overweight/obesity in a Shanghai twin cohort. We also wanted to study their association and explore possible risk factors for the discordance of overweight/obesity within twins. This was an internal casecontrol study designed for twins. The 2012 Shanghai Twin Registration System baseline survey data of a total of 3417 twin pairs were statistically analyzed using SPSS22 software. Results show that the body mass index (BMI) of the Shanghai twin population increased with age. Twins with a high birth weight had a higher BMI and a higher rate of overweight and obesity; 0- to 6-year-old twins, male twins and dizygotic (DZ) twins had higher rates of overweight/obesity than other groups. The greater the discordant birth weight rate of twins, the more obvious the difference in BMI $(p<.05)$. There was a significant difference in overweight/obesity between twins with a relative difference of birth weight $\geq 15 \%$ in DZ twins $(p<.05)$. DZ twins, male twins and 0 - to 6 -year-old twins were more likely to be discordant in overweight/obese than others. The discordant birth weight within twins was not a risk factor for discordant overweight/obesity. However, attention should be paid to childhood obesity, and appropriate interventions should be made at the appropriate time. Genetics may play an important role in the occurrence and development of overweight/obesity. In conclusion, discordant growth and development in the uterus early in life may not lead to discordant weight development in the future.
\end{abstract}

Keywords: Overweight/obesity; twin study; birth weight

(Received 13 October 2020; accepted 15 December 2020; First Published online 1 March 2021)

Overweight and obesity have become one of the most important public health problems affecting the health of adults and children worldwide. With the improvement of residents' living standards and changes in lifestyles in China, the prevalence of overweight/ obesity is rising rapidly in each population (Jun et al., 2012). Studies have shown that the occurrence of obesity may be related to intrauterine growth and development in early life (Barker, 2003). Birth weight is a simple, reliable and easily available indicator reflecting intrauterine growth and development of the fetus, and its relationship with the occurrence of overweight/obesity has attracted the attention of researchers in recent years (Ren et al., 2013). In this study, we utilized the special cohort research method for twin populations and effectively controlled the influence of confounding factors introduced by overweight/obesity in non-twins, aiming to achieve a better analysis of the difference in birth weight between monozygotic (MZ) twins and dizygotic (DZ) twins and its relationship with overweight/obesity, and to

Author for correspondence: Wu Fan, Email: wufan@shmu.edu.cn; and Wang Wenjing, Email: wangwenjing@scdc.sh.cn

Cite this article: Liao P, Wang W-J, Yu H-T, Zang J-J, Qian N-S, He X, Gao W-J, Yu C-Q, Li L-M, and Wu F. (2021) Differences and Correlation Analysis of Birth Weight and Overweight/Obesity in Shanghai Twin Cohort. Twin Research and Human Genetics 24: 29-36, https://doi.org/10.1017/thg.2021.2 look for clues for the correlation between early life development and overweight/obesity. We also compared the roles of genetic factors and environmental factors in overweight/obesity.

\section{Methods}

\section{Participants}

Based on the 2012 China Twin Registry System-Shanghai Twin Registry system Phase I baseline survey data (Li et al., 2013), and after excluding twin pairs with discordant sex and missing data, a total of 3393 twin pairs aged 0-64 years were included in this study. The cohort study was reviewed by the Peking University Biomedical Ethics Committee (IRB00001052-11029). All the participants volunteered to participate in this survey and signed the informed consent form. Parents or guardians of minors under 18 years signed the informed consent form.

All pairs of twins included in this study were aged 18.24 \pm 13.43 years. They comprised 1976 pairs of MZ twins (58.2\%) and 1417 pairs of DZ twins (41.8\%). There were 1667 pairs of male twins (49.1\%) and 1726 pairs of female twins (50.9\%).

The birth weight of the participants was self-reported using the questionnaire, and the current height, current weight and other indicators were measured at the survey site. 


\section{Definition and Grouping of Evaluation Indicators}

Birth weight $(\mathrm{kg})$. According to measures in the literature by Liu et al. (2016), the twins were divided into three groups by birth weight: $<2.5 \mathrm{~kg}$ (low birth weight), $\geq 2.5 \mathrm{~kg}$ and $<3.0 \mathrm{~kg}$ (normal birth weight) and $\geq 3.0 \mathrm{~kg}$ (high birth weight).

Relative birth weight difference (\%). The birth weight difference of the same pair of twins was calculated by the birth weight of the higher twin minus that of the lower twin; the relative difference in birth weight of the same pair of twins was calculated by using the formula: the difference in birth weight of the twins/birth weight of the higher twin $\times 100 \%$. According to the calculated relative difference in birth weight (Blickstein, 1991; Blickstein \& Lancet, 1988), a birth weight $\geq 15 \%$ was used as the criterion for discordant birth weight and the twin pairs were divided into two groups, that is, twins with a relative difference in birth weight $<15 \%$ and twins with a relative difference in birth weight $\geq 15 \%$.

Body mass index. According to the formula for body mass index (BMI), that is, weight $(\mathrm{kg}) /$ height $\left(\mathrm{m}^{2}\right)$, the BMI of twins was calculated.

Criteria for judging overweight/obesity. Depending on different age groups, the criteria for overweight and obesity were different. According to Shanghai preschool children's growth and development standards, for children aged $0-5$ years, the diagnostic criteria for underweight, overweight and obesity for children $<5$ years old (2006 World Health Organization Standards) were adopted; for children $>5$ years old and $\leq 6$ years old, the BMI for children and adolescents aged 0-19years old (2007 World Health Organization Standards) was adopted; for children and adolescents aged 7-17 years, the BMI reference norm for screening overweight and obesity in Chinese children and adolescents was adopted; for adults $\geq 18$ years, the BMI reference norm for overweight and obesity in Chinese adults was adopted.

Age grouping. The twins in this study were divided into infants and young children ( $\leq 6$ years old; De Onis et al., 2007; World Health Organization, 2006), children and adolescents (7-17 years old; Group of Chinese Obesity Task Force, 2004), and adults ( $\geq 18$ years old; Department of Disease Control Ministry of Health, PR China, 2006) with reference to the criteria for overweight/obesity and the characteristics of each age group.

\section{Zygosity Judgment}

Zygosity judgment is used as a basis for data analysis and research. In this study, we assessed the zygosity of twins using the questionnaire method. First, opposite-sex twins were regarded as DZ, but they were not included in the scope of the study. Second, for samesex twins, a model was built according to gender, age and the question for the basic registration of twins, that is, 'Do you think you and your twin brother/sister looked alike when you were young?' Finally, we judged the zygosity of 1976 pairs of MZ twins and 1417 pairs of DZ twins using genetic analysis. The consistency between the judgment result by this method and that of the gold standard 'genetic method' reached 0.88 (95\% CI [0.82, 0.92]) (Zhou et al., 2015).

\section{Statistical Analysis}

This study adopted an intrapair control design. In the statistical analyses, the twins were regarded as pairs of individuals and SPSS22 software was used for data about birth weight, BMI, overweight/obesity of MZ twins and DZ twins of different age groups and sexes, and distribution of discordant birth weight and discordant overweight/obesity. A paired chi-square test was used to analyze the discordant birth weight and discordant overweight/obese outcomes of Shanghai twins in terms of zygosity, age and sex.

The rank sum test of two related samples was used to analyze whether there were differences in birth weight and BMI within MZ and $\mathrm{DZ}$ pairs. A chi-square test of two related samples was used to analyze whether there was a difference in overweight/obesity within MZ and DZ pairs, and the correlation analysis between discordant birth weight and overweight/obesity. The rank sum test was used to analyze the correlation between discordant birth weight and the difference in BMI within the twin pairs.

Paired logistic regression was used to analyze the correlation between discordant overweight/obesity and zygosity, intrapair BMI difference, age and discordant birth weight of Shanghai twins.

\section{Results}

The Shanghai twins in this study had an average birth weight of $2.47 \pm 0.49 \mathrm{~kg}$ and an average BMI of $19.36 \pm 4.47 \mathrm{~kg} / \mathrm{m}^{2}$. The BMI of Shanghai twins in infants and young children ( $0-6$ years old), children and adolescents ( $7-17$ years old), and adults ( $\geq 18$ years old) increased with the respective age group, and twins with higher birth weight had higher BMI (Figure 1). The BMI of male twins was slightly higher than that of female twins of the same age group and the same birth weight. The distribution of BMI was similar among twins of different zygosity (See Appendix Table A1).

Among Shanghai twins in the age groups of infants and young children ( $0-6$ years), children and adolescents ( $7-17$ years), and adults ( $\geq 18$ years), the overweight/obesity standardized rate was higher in those aged 0-6 years, reaching 36.7\% (Appendix Table A1). Twins with a higher birth weight also had a higher rate of overweight/obesity (Figure 1). Male twins had a much higher overweight/obesity rate than female twins of the same age group and the same birth weight (Appendix Table A1). Among twins of different zygosity in the age group $0-6$ years, the overweight/obesity rate was significantly higher in DZ twins than in MZ twins and this trend was more notable with higher birth weight (Figure 2).

According to previous reports (Blickstein, 1991), with the relative difference in birth weight $\geq 15 \%$ as the criterion for discordant birth weight of twins, intrapair discordant birth weight slightly varied with zygosity, age group and sex (Table 1). Statistical analyses showed that discordant birth weight varied between $\mathrm{MZ}$ twins and DZ twins $\left(\chi^{2}=19.563, p<.001\right)$, but was not related to sex $\left(\chi^{2}=\right.$ $0.222, p=.653)$. The distribution of discordant overweight/obesity outcome of Shanghai twins was statistically significant according to zygosity $\left(\chi^{2}=46.933, p<.001\right)$, age $\left(\chi^{2}=24.709, p<.001\right)$, and $\operatorname{sex}\left(\chi^{2}=11.577, p=.001\right)$ (Table 1$)$.

This study utilized an intrapair control design to conduct statistical analyses, which could provide insight into the correlation between exposure factors during the fetal period and risks of future diseases (Dwyer \& Blizzard, 2005).

The paired rank sum test results of two related samples showed that there was an intrapair difference in birth weight $(p<.05)$ and BMI $(p<.05)$. The rank sum test analysis between the relative difference in birth weight and the difference in BMI showed that the 


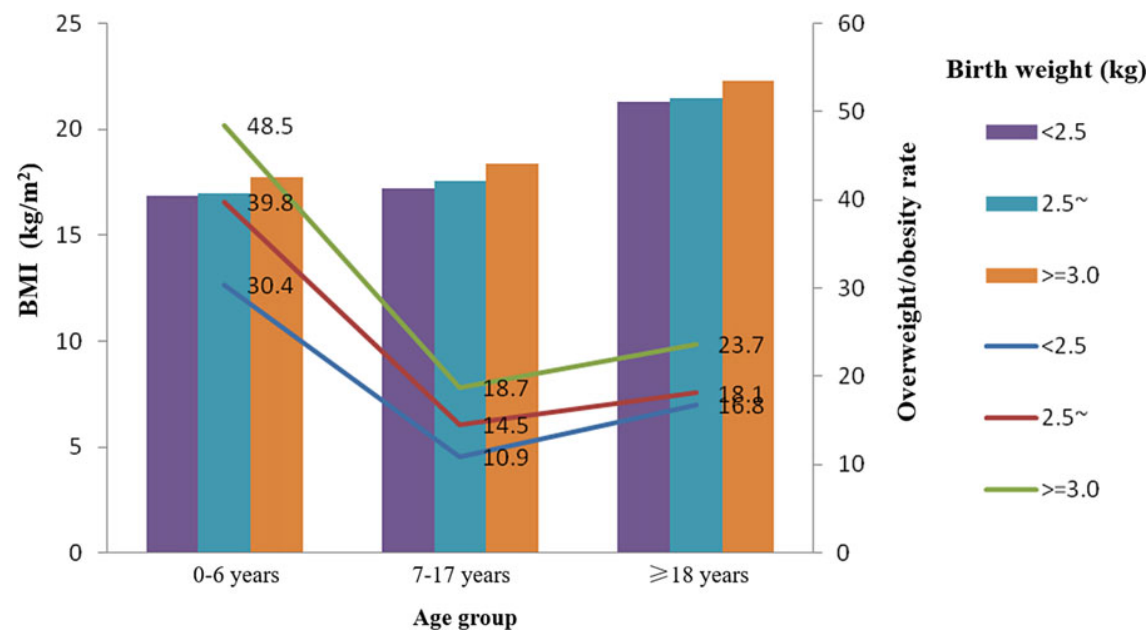

Fig. 1. Distribution of BMI and overweight/obesity rate of Shanghai twin cohorts of different age groups and birth weights. BMI, body mass index.

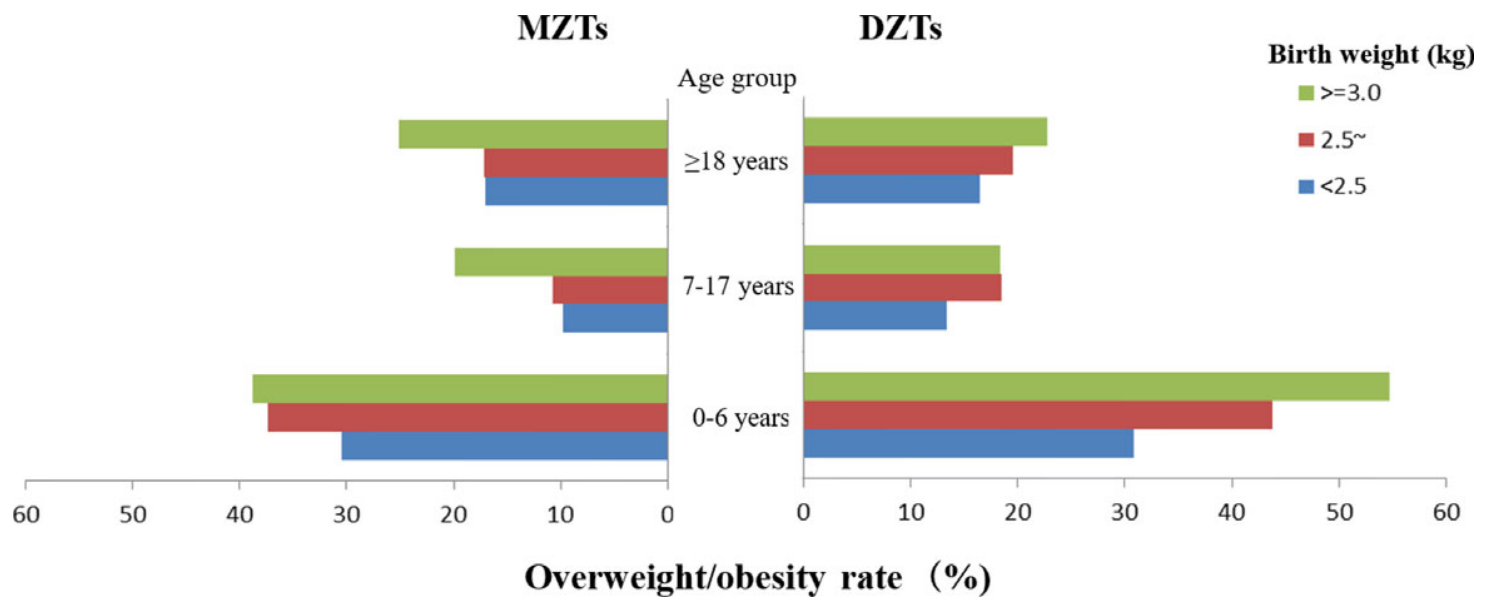

Fig. 2. Distribution of zygosity and overweight/obesity rate of Shanghai twin cohorts of different age groups and birth weights. MZ twins, monozygotic twins; DZ twins, dizygotic twins.

greater the discordant birth weight rate of twins, the more obvious the difference in BMI, and the intergroup difference was statistically significant $(p<.05)$ (Table 2$)$.

The paired chi-square test results of two related samples showed that there was no difference in overweight/obesity in MZ pairs $(p>.05)$, and there was a difference in overweight/obesity in DZ pairs $(p<.05)$. The discordant birth weight was further subjected to stratified analysis, and it was found that the difference was statistically significant in DZ twins with a relative birth weight difference of $\geq 15 \%(p<.05)$ (Table 3$)$. It can be seen from Table 3 that there were 377 pairs of DZ pairs with discordant birth weight. In terms of overweight/obesity, as of the date of the survey, 263 pairs were consistently normal/lean, 55 pairs were consistently overweight/obese and 59 pairs had a discordant outcome, with one being overweight/obese and the other one being normal/lean. Considering the difference in birth weight of the twins, it was further found that among the 59 pairs of DZ twins with discordant obesity outcomes, 37 pairs of high birth weight twins developed overweight/obesity later and the other 22 pairs of high birth weight twins became normal/lean instead, showing a positive trend overall.

With discordant overweight/obesity as the dependent variable, and zygosity, sex, discordant birth weight and twin age as independent variables, a univariate paired logistic regression analysis was performed. The results of the analysis showed that the MZ twins had an incidence of discordant overweight/obesity outcome 0.483 times that of DZ twins; male twins had an incidence of discordant overweight/obesity outcome 1.439 times that of female twins, and infants and young children aged 0-6 years had a higher risk of discordant overweight/obesity outcome than twins aged $7-17$ years and adult twins aged $\geq 18$ years (Table 4 ). The discordant birth weight within twins did not affect the future development of discordant overweight/obesity (Table 4).

The variables with meaningful results from the above-mentioned univariate regression analysis were incorporated into the multivariate paired logistic regression model for analysis. The analysis results were consistent with the univariate paired logistic regression analysis. Odds ratios for $\mathrm{MZ}$, male, age-discordant overweight/obesity were $0.491,1.419,1.315$ and 0.613 respectively. This means that MZ twins were more likely to have a consistent phenotype (overweight/obesity outcome) than DZ twins $\left(\chi^{2}=43.200\right.$, $p<.05)$; male twins were more likely to have discordant overweight/obese outcomes than female twins $\left(\chi^{2}=10.427, p<.05\right)$; infant and young children aged $0-6$ years had a risk of discordant overweight/obesity 1.315 times that of twins aged $\geq 18$ years $\left(\chi^{2}=\right.$ $5.170, p<.05)$; and twins aged $\geq 18$ years also had a high risk 
Table 1. Distribution of discordant birth weight and discordant overweight/obesity of Shanghai twins

\begin{tabular}{|c|c|c|c|c|c|c|}
\hline Discordant phenotype & \multicolumn{3}{|c|}{ Age $^{*}$} & \multicolumn{2}{|c|}{ Sex $^{*}$} & Total \\
\hline \multicolumn{7}{|c|}{ Relative difference in birth weight (\%) } \\
\hline$<15 \%$ & 415 (81.9) & $413(82.6)$ & $750(77.4)$ & $766(80.0)$ & $812(79.7)$ & $1578(79.9)$ \\
\hline$\geq 15 \%$ & $92(18.1)$ & $87(17.4)$ & $219(22.6)$ & $191(20.0)$ & $207(20.3)$ & $398(20.1)^{\mathrm{a}}$ \\
\hline$<15 \%$ & $296(76.3)$ & $235(73.7)$ & $509(71.7)$ & $526(74.1)$ & $514(72.7)$ & $1040(73.4)$ \\
\hline$\geq 15 \%$ & $92(23.7)$ & $84(26.3)$ & $201(28.3)$ & $184(25.9)$ & $193(27.3)$ & $377(26.6)^{\mathrm{a}}$ \\
\hline Total discordant cases & $184(20.6)$ & $171(20.9)$ & $420(25.0)$ & $1667(22.5)$ & $1726(23.2)$ & $775(22.8)$ \\
\hline \multicolumn{7}{|l|}{ Overweight/obesity outcome } \\
\hline \multicolumn{7}{|l|}{$M Z$} \\
\hline Consistent cases & $314(80.9)$ & $281(88.1)$ & $591(83.2)$ & $570(80.3)$ & $616(87.1)$ & $1186(83.7)$ \\
\hline Discordant cases & $74(19.1)$ & $38(11.9)$ & $119(16.8)$ & $140(19.7)$ & $91(12.9)$ & $231(16.3)^{b}$ \\
\hline Total discordant cases & $137(15.3)^{c}$ & $62(7.6)^{c}$ & $202(12.0)^{c}$ & $229(13.7)^{d}$ & $172(10.0)^{d}$ & $401(11.8)$ \\
\hline
\end{tabular}

MZ, monozygotic; DZ, dizygotic.

${ }^{\star}$ The figures outside the parentheses indicate the number of twin pairs, and the figures inside the parentheses indicate the incidence rate (\%).

${ }^{a} p<.001$, discordant birth weight varied between MZ and DZ twins.

${ }^{\mathrm{b}} p<.001$, the discordant overweight/obesity outcome varied between MZ and DZ twins.

${ }^{c} p<.001$, the discordant overweight/obesity outcome varied between twins of different age groups.

${ }^{\mathrm{d}} p<.001$, the discordant overweight/obesity outcome varied between twins of different sexes.

Table 2. Rank sum test of discordant birth weight and BMI difference of twins

\begin{tabular}{|c|c|c|c|}
\hline $\begin{array}{l}\text { Relative difference in } \\
\text { birth weight (\%) }\end{array}$ & $\begin{array}{l}\text { Number of } \\
\text { twin pairs }\end{array}$ & $\begin{array}{l}\text { BMI pairing } \\
\text { difference }(\bar{x} \pm s)\end{array}$ & $p$ Value \\
\hline \multicolumn{4}{|l|}{$M Z$} \\
\hline & 1578 & $0.86 \pm 2.87$ & \\
\hline$\geq 15.0$ & 398 & $0.92 \pm 1.25$ & \\
\hline Total & 1976 & $0.87 \pm 2.62$ & .001 \\
\hline \multicolumn{4}{|l|}{$\mathrm{DZ}$} \\
\hline & 1040 & $1.44 \pm 1.76$ & \\
\hline$\geq 15.0$ & 377 & $1.88 \pm 6.55$ & \\
\hline Total & 1417 & $1.56 \pm 3.70$ & .006 \\
\hline
\end{tabular}

BMI, body mass index; MZ, monozygotic; DZ, dizygotic.

of discordant overweight/obesity outcome, while twins aged $7-17$ years had a relatively consistent overweight/obesity outcome $\left(\chi^{2}=10.232, p<.05\right)$ (Table 5).

\section{Discussion}

Obesity is a metabolic disorder that is attributable to multiple factors. Its etiology is complex. This is mostly the result of the combined effect of genetic and environmental factors. It is an important cause of many chronic diseases such as tumors, hypertension and diabetes and can indirectly increase the national medical and health economic burden (Zhao et al., 2008). Therefore, it is imperative to conduct etiological research on obesity. The Barker hypothesis (Barker, 2003) proposed that prenatal exposure is related to adult diseases, especially chronic diseases such as hypertension, diabetes and obesity. Although it is difficult to directly estimate the growth, development and nutritional status of a fetus, birth weight can be used as a sound and easily available biological evaluation indicator to reflect this. Many studies have shown that birth weight is related to obesity in children and adults (Jelenkovic et al., 2017; Loos et al., 2001; Parsons et al., 2001). However, research on the correlation between birth weight and diseases is always affected by various confounding factors, such as age, sex, fetal intrauterine environment and postnatal growth environment, which make it difficult to obtain a consistent and strong conclusion (Rossi, 2010). In a twin population cohort study, confounding factors, such as sex, age, intrauterine environment during the fetal period, early environment and maternal exposure, can be well controlled. If the phenotypic similarity of MZ twins is higher than that of DZ twins, this may be due to the increased degree of genetic similarity, suggesting that inheritance plays an important role in overweight/obesity. Therefore, the twin population cohort study is an important method to study the etiology of complex diseases (Dwyer \& Blizzard, 2005; Morley \& Dwyer, 2005; Qihua et al., 2015). In this study, the twin population cohort and birth weight indicator were combined to explore the correlation between fetal growth and development in the uterus and future overweight/obesity.

In this study, we found that twins with a higher birth weight had a higher BMI and overweight/obesity rate, showing a positive trend, and this trend was particularly significant in infants and young children aged 0-6 years and became less significant in adulthood. These findings are consistent with other research findings at 
Table 3. Difference analysis of overweight/obesity in different relative birth weight groups of Shanghai twins

\begin{tabular}{|c|c|c|c|c|c|}
\hline Relative difference in birth weight (\%) & $\frac{\text { Twin grouping }}{\text { Twin } 1 \text { obesity group }}$ & \multicolumn{2}{|c|}{ Twin 2 obesity group } & Chi-square value $\left(\chi^{2}\right)$ & $p$ Value \\
\hline \multicolumn{6}{|l|}{ MZ } \\
\hline & Normal/lean & 58 & 1183 & & \\
\hline$\geq 15.0$ & Overweight/obese & 63 & 20 & 0.735 & .392 \\
\hline Total & & 394 & 1582 & 3.676 & .055 \\
\hline \multicolumn{6}{|l|}{ DZ } \\
\hline & Overweight/obese & 168 & 95 & 1.680 & .195 \\
\hline & Normal/lean & 77 & 700 & & \\
\hline$\geq 15.0$ & Overweight/obese & 55 & 38 & 4.339 & .036 \\
\hline
\end{tabular}

$\mathrm{MZ}$, monozygotic; DZ, dizygotic.

Table 4. Univariate paired logistic regression analysis of discordant overweight/ obesity of Shanghai twins

\begin{tabular}{lccc}
\hline Independent variable & $p$ Value & OR value & $95 \% \mathrm{Cl}$ \\
\hline $\begin{array}{l}\text { Zygosity (with DZ twins } \\
\text { as reference) }\end{array}$ & .001 & 0.483 & {$[0.391,0.597]$} \\
\hline $\begin{array}{l}\text { Sex (with reference } \\
\text { female twins as reference) }\end{array}$ & .001 & 1.439 & {$[1.166,1.776]$} \\
\hline $\begin{array}{l}\text { Discordant birth weight } \\
\text { (with difference } \\
<15 \% \text { as reference) }\end{array}$ & .859 & 1.023 & {$[0.799,-1.309]$} \\
\hline $\begin{array}{l}\text { Age group (with twins aged } \\
\geq 18 \text { years as reference) }\end{array}$ & & & \\
\hline 0-6 years & .019 & 1.322 & $1.046,1.607$ \\
\hline 7-17 years & .001 & 0.599 & $0.445,0.807$ \\
\hline
\end{tabular}

DZ, dizygotic; OR, odds ratio; $\mathrm{Cl}$, confidence interval.

home and abroad (Loos et al., 2001; Parsons et al., 2001; Woo Baidal et al., 2016). This article also confirms some existing findings (Baird et al., 2005; Ekelund et al., 2007). Fetal intrauterine growth will affect BMI and overweight/obesity in the future, and early life weight as an indicator can predict the trend of overweight/obesity in preschool children. In addition, the incidence of overweight/obesity in infants and young children aged 0-6 years reached as high as $36.7 \%$, which was close to the level of developed countries in the survey year (National Center for Health Statistics (US), 2012; Ogden et al., 2014). This may be related to the growth in living standards in China (Chen et al., 2004). It may also be because the quantity of adipocytes in infants and young children has reached its maximum, and there is only a small increase after puberty (Bingrong, 2007; Ong et al., 2000). The paired logistic regression analysis also showed that infants and young children aged 0-6 years were more likely to have discordant overweight/ obesity. Studies have shown that obese children are more likely than their normal-weight peers to be obese in the future (Fuentes et al., 2003; McTigue et al., 2002). Therefore, we must emphasize the impact of overweight/obesity in this age group. Moreover, preschool twins are usually raised together; this means there are fewer nonshared environmental factors and it is easier to eliminate the impact of environmental factors on diseases, so that the problems can be considered purely from the perspective of genetics. Therefore, exploring the causes of overweight/obesity in this age group may offer a relatively ideal research direction.

This study also revealed that the discordant birth weight rate was higher in DZ twins than in MZ twins. As of 2012, the discordant birth weight rate in Shanghai twins reached $22.8 \%$, which was close to the results in the national data of $22.4 \%$ (Liu et al., 2015); and a foreign study found that about $25 \%$ of twins had a discordant birth weight of $\geq 15 \%$ (Blickstein \& Kalish, 2003). The discordant birth weight rate of Shanghai DZ twins was $26.6 \%$, which was higher than the discordant birth weight rate of $20.1 \%$ in MZ twins. This intergroup difference is significant and consistent with the national trend (Liu et al., 2015). A slight birth weight inconsistency — that is, $<15 \%$ - is considered to be a normal difference between twins, while a notable discordant birth weight rate of $\geq 15 \%$ between twins may be caused by the growth-restricted mode to adapt to the limited uterine space with an increase in the gestational age (Blickstein \& Kalish, 2003). The potential causes of a higher discordant birth weight rate in DZ twins compared with MZ twins have not yet been fully revealed. It is speculated that this may be mainly due to genetic factors. The specific causes are open to future studies.

This study also observed that DZ twins had a higher discordant overweight/obesity rate than MZ twins. Further intrapair statistical analysis of the difference in overweight/obesity showed that there was no difference in overweight/obesity between MZ twins and that there was a difference in overweight/obesity in DZ twins, with a relative difference of $\geq 15 \%$ in birth weight. Subsequent paired univariate and multivariate logistic regression analysis showed that DZ twins had a higher risk of discordant overweight/obesity than $M Z$ twins. At the same age, early intrauterine and extrauterine environmental factors, and genetic factors (MZ twins, 100\%; DZ twins, 50\%) mean that MZ twins have a higher phenotype similarity than DZ twins; therefore, it is speculated that genetic factors may play a notable role in the occurrence and development of overweight/obesity. Genetic similarity may be more likely to have the same outcome for final overweight/obesity. However, this 
Table 5. Multivariate paired logistic regression analysis of discordant overweight/obesity of Shanghai twins*

\begin{tabular}{lcccc}
\hline & $\begin{array}{c}\text { Chi-square } \\
\text { Independent variable }\end{array}$ & & \\
\hline value $\left(\chi^{2}\right)$ & $p$ Value & OR value & $95 \% \mathrm{Cl}$ \\
\hline Zygosity & & & & \\
\hline MZ & 43.200 & .001 & 0.491 & {$[0.397,0.607]$} \\
\hline DZ (reference) & & & & \\
\hline Sex & & & & \\
\hline Male & 10.427 & .001 & 1.419 & {$[1.148,1.755]$} \\
\hline Female (reference) & & & & \\
\hline Age group & & & & \\
\hline 0-6 years & 5.170 & .023 & 1.315 & {$[1.039,1.666]$} \\
\hline 7-17 years & 10.232 & .001 & 0.613 & {$[0.454,0.827]$} \\
\hline$\geq 18$ years (reference) & & & & \\
\hline
\end{tabular}

$\mathrm{MZ}$, monozygotic; DZ, dizygotic; OR, odds ratio; $\mathrm{Cl}$, confidence interval.

${ }^{*}$ Reference means the same overweight/obesity outcome.

conclusion needs to be further analyzed through structure equation modeling (SEM) software in the next stage of research. It is well known that obesity is mostly the result of the combined effect of genetic and environmental factors, although it has always been controversial whether genetic or environmental factors play a greater role. Some scholars have suggested that although the obesity environment is ubiquitous, the difference in body weight has increased in recent decades (Llewellyn \& Wardle, 2015). Studies in many twins with discordant weights have found that obesity or the quantity and size of fat cells related to obesity and the mitochondrial DNA metabolism pathways that regulate the distribution of adipose tissues are highly heritable (Elks et al., 2012; Llewellyn \& Wardle, 2015; Xing et al., 2008) and that the occurrence and development of obesity may be more related to genetic factors. In addition, the paired logistic regression analysis showed that the discordant birth weight of Shanghai twins was not an influencing factor of discordant overweight/obesity later. However, the paired chi-square test showed that DZ twins with a relative birth weight difference of $\geq 15 \%$ had a statistically significant difference in overweight/obesity. This reminds us of the obesity behavioral susceptibility theory of obesity proposed by some scholars, that is, the genetic susceptibility to obesity is partly due to the appetite phenotype. The theory proposes that from the first few months of life, appetite affects the development of weight (van Jaarsveld, Boniface et al., 2014; van Jaarsveld, Llewellyn et al., 2011), that individual differences in appetite characteristics have a strong genetic basis (Carnell et al., 2008; Llewellyn et al., 2010) and that single nucleotide polymorphisms related to obesity will affect weight by affecting appetite (Llewellyn et al., 2014; Wardle et al., 2008). This may explain the difference in overweight/obesity in intrapair analysis of DZ twins, which may be due to the different genetic susceptibility to appetite of DZ twins. This difference occurs in DZ twins with discordant birth weights. It is speculated that this genetic difference, which interacts with susceptibility to obesity, may exist as early as the fetal period and affect the intrauterine development and future growth of the fetus, which is directly reflected in the birth weight, that is, one twin having a higher birth weight and the other having a lower birth weight. Twins with a higher birth weight may have a better appetite, which would later lead to higher weight. Conversely, twins with a lower birth weight may have a poorer appetite and have a lower weight later. This suggests that early preventative intervention and selfcontrol of the appetite may reduce the incidence of obesity in individuals with high susceptibility (van Jaarsveld et al., 2014).

This study has certain limitations. First, the indicator of birth weight was obtained through self-reported questionnaires, which could include recall bias. However, many studies have shown that parents' recall of their children's birth weight is relatively accurate, and the difference between the birth weight obtained by selfreporting and the actual measurement data is small (O'Sullivan et al., 2000; Pless \& Pless, 1995). Second, this study obtained less information about the mothers of the study participants. Studies have shown that maternal obesity can change the relationship between birth weight and future obesity in the offspring (The et al., 2010) and that the copy number of mitochondrial genes and metabolism related to obesity is also related to maternal inheritance (Xing et al., 2008). Third, this study found that the Shanghai twin cohort had a low number of twin pairs with discordant overweight/obesity outcomes. In future, while expanding the survey sample size, we will continue to focus on follow-up investigations, observe changes in disease outcomes and supplement existing data to obtain better results. Finally, although the twin cohort research method can offset the influence of genetic factors and shared environmental factors on diseases, some nonshared environmental factors have not yet been investigated. For example, the difference in birth weight of twins may cause their mothers to raise or feed the two children in different ways, which in turn will affect the overweight/obesity outcome, and twins may have different weight development due to different appetites. These different nonshared environmental factors should be included in future investigations and studies.

In summary, the birth weight of twins is closely related to BMI and overweight/obesity and twins with a higher birth weight have a higher risk of overweight/obesity in the future. Intrauterine growth of the fetus affects the future BMI and the overweight/obesity outcome. The correlation between the two is more obvious in children aged 0-6 years. Therefore, attention must be paid to the development of obesity in children. Appropriate intervention can be implemented through appetite control to promote the health development of children's weight. Intrapair analysis of twins showed that discordant birth weight will not necessarily lead to discordant overweight/obesity outcome in the future, with no correlation between the two. This indicates that the discordant weight development of twins is not related to the discordant intrauterine growth and development at the beginning of life. In the future, it will be necessary to conduct more epidemiological surveys of twins, and supplement maternal information about feeding methods, appetite and other information, and further analyze the possible mechanisms of the occurrence and development of overweight/ obesity. Although this twin cohort study found that genetics plays a great role in overweight/obesity, and the effect of environmental factors may also be caused by different individual genetic sensitivity, the degree and mode of actions of genetics on overweight/ obesity require further in-depth molecular biology research.

Acknowledgements. We thank all participants for their contributions to the cohort study. All investigators are acknowledged for their help in the collection of the data.

Financial support. This study was supported by Scientific Research Project of Shanghai Municipal Health Commission, China (201940114), Special Research Project of Health Public Service, Ministry of Health, China (201502006 and 201002007).

Conflict of interest. None. 


\section{References}

Baird, J., Fisher, D., Lucas, P., Kleijnen, J., Roberts, H., \& Law, C. (2005). Being big or growing fast: systematic review of size and growth in infancy and later obesity. BMJ, 331, 929.

Barker, D. J. P. (2003). The developmental origins of adult disease. Journal of the American College of Nutrition, 18, 733-736.

Bingrong, L. (2007). Study on relationship between birth weight and child simple obesity. Chinese Journal of Public Health, 23, 653-654.

Blickstein, I. (1991). The definition, diagnosis, and management of growthdiscordant twins: An international census survey. Acta Geneticae Medicae et Gemellologiae, 40, 345-351.

Blickstein, I., \& Kalish, R. B. (2003). Birthweight discordance in multiple pregnancy. Twin Research, 6, 526-531.

Blickstein, I., \& Lancet, M. (1988). The growth discordant twin. Obstetrical \& Gynecological Survey, 43, 509-515.

Carnell, S., Haworth, C. M., Plomin, R., \& Wardle, J. (2008). Genetic influence on appetite in children. International Journal of Obesity, 32, 1468-1473.

De Onis, M., Onyango, A. W., Borghi, E., Siyam, A., Nishida, C., \& Siekmann, J. (2007). Development of a WHO growth reference for school-aged children and adolescents. Bulletin of the World Health Organization, 85, 660-667.

Department of Disease Control Ministry of Health, PR China. (2006). Guidelines for the prevention and control of overweight and obesity in Chinese adults. People's Medical Publishing House.

Dwyer, T., \& Blizzard, L. (2005). A discussion of some statistical methods for separating within-pair associations from associations among all twins in research on fetal origins of disease. Paediatric and Perinatal Epidemiolog, 19, 48-53.

Ekelund, U., Ong, K. K., Linné, Y., Neovius, M., Brage, S., Dunger, D. B., . . Rössner, S. (2007). Association of weight gain in infancy and early childhood with metabolic risk in young adults. Journal of Clinical Endocrinology and Metabolism, 92, 98-103.

Elks, C. E., den Hoed, M., Zhao, J. H., Sharp, S. J., Wareham, N. J., Loos, R. J., \& Ong, K. K. (2012). Variability in the heritability of body mass index: A systematic review and meta-regression. Frontiers in Endocrinology, 3, 29.

Fuentes, R. M., Notkola, I. L., Shemeikka, S., Tuomilehto, J., \& Nissinen, A. (2003). Tracking of body mass index during childhood: a 15-year prospective population-based family study in eastern Finland. International journal of obesity and Related Metabolic Disorders, 27, 716-721.

Group of China Obesity Task Force. (2004). Body mass index reference norm for screening overweight and obesity in Chinese children and adolescents. Chinese Journal of Epidemiology, 25, 97-102.

Jelenkovic, A., Yokoyama, Y., Sund, R., Pietiläinen, K. H., Hur, Y. M., Willemsen, G., ... Silventoinen, K. (2017). Association between birthweight and later body mass index: An individual-based pooled analysis of 27 twin cohorts participating in the CODATwins project. International Journal of Epidemiology, 46, 1488-1498.

Jun, M., Cihe, C., \& Haijun, W. (2012). The trend analysis of overweight and obesity in Chinese students during 1985-2010. Chinese Journal of Preventive Medicine, 46, 776-780.

Li, L., Gao, W., Yu, C., Lv, J., Cao, W., Zhan, S., ... Hu, Y. (2013). The Chinese national twin registry: An update. Twin Research \& Human Genetics, 16, 86-90.

Liu, Q., Yu, C., Gao, W., Cao, W., Lyu, J., Wang, S., . . L Li, L. (2015). Change trend of birth weight of twins in China, 1995-2012. Chinese Journal of Epidemiology, 36, 115-118.

Liu, Q., Yu, C., Gao, W., Cao, W., Lyu, J., Wang, S., . . Li, L. (2016). A co-twin control study on birth weight, overweight and obesity among children younger than 18 years old in China. Chinese Journal of Epidemiology, 37, 464-468.

Llewellyn, C. H., Trzaskowski, M., van Jaarsveld, C., Plomin, R., \& Wardle, J. (2014). Satiety mechanisms in genetic risk of obesity. JAMA Pediatrics, 168, 338-344.

Llewellyn, C. H., van Jaarsveld, C. H., Johnson, L., Carnell, S., \& Wardle, J. (2010). Nature and nurture in infant appetite: analysis of the Gemini twin birth cohort. American Journal of Clinical Nutrition, 91, 1172-1179.
Llewellyn, C., \& Wardle, J. (2015). Behavioral susceptibility to obesity: Geneenvironment interplay in the development of weight. Physiology \& Behavior, 152, 494-501.

Loos, R. J., Beunen, G., Fagard, R., Derom, C., \& Vlietinck, R. (2001). Birth weight and body composition in young adult men $3 / 4$ A prospective twin study. International Journal of Obesity and Related Metabolic Disorders, 25, 1537-1545.

McTigue, K. M., Garrett, J. M., \& Popkin, B. M. (2002). The natural history of the development of obesity in a cohort of young U.S. adults between 1981 and 1998. Annals of Internal Medicine, 136, 857-864.

Morley, R., \& Dwyer, T. (2005). Studies of twins: what can they tell us about the fetal origins of adult disease? Paediatric and Perinatal Epidemiology, 19, 2-7.

National Center for Health Statistics (US). (2012). Health, United States, 2011: With Special Feature on Socioeconomic Status and Health.

Ogden, C. L., Carroll, M. D., Kit, B. K., \& Flegal, K. M. (2014). Prevalence of childhood and adult obesity in the United States, 2011-2012. JAMA, 311, 806-814.

Ong, K. K., Ahmed, M. L., Emmett, P. M., Preece, M. A., \& Dunger, D. B. (2000). Association between postnatal catch-up growth and obesity in childhood: prospective cohort study. BMJ, 320, 967-971.

O'Sullivan, J. J., Pearce, M. S., \& Parker, L. (2000). Parental recall of birth weight: how accurate is it? Archives of Disease in Childhood, 82, 202-203.

Parsons, T. J., Power, C., \& Manor, O. (2001). Fetal and early life growth and body mass index from birth to early adulthood in a 1958 British cohort: Longitudinal study. BMJ, 323, 1331-1335.

Pless, C. E., \& Pless, I. B. (1995). How well they remember. The accuracy of parent reports. Archives of Pediatrics \& Adolescent Medicine, 149, 553-558.

Qihua, T., Lene, C., Jacob, V. B. H., \& Kaare, C. (2015). Twin methodology in epigenetic studies. Journal of Experimental Biology, 218, 134-139.

Ren, J., Wu, J., Ji, M., Rong, F., Li, Y., Gao, E., \& Ji, H. (2013). The effect of high birth weight on overweight and obesity in childhood and adolescence. A cohort study in China. Saudi Medical Journal, 34, 623-631.

Rossi, C. E. (2010). Birth weight and obesity in children and adolescents: a systematic review. Revista Brasileira De Epidemiologia, 13, 246-258.

The, N. S., Adair, L. S., \& Gordon-Larsen, P. (2010). A study of the birth weight-obesity relation using a longitudinal cohort and sibling and twin pairs. American Journal of Epidemiology, 172, 549-557.

van Jaarsveld, C. H., Boniface, D., Llewellyn, C. H., \& Wardle, J. (2014). Appetite and growth: a longitudinal sibling analysis. JAMA Pediatrics, $168,345-350$.

van Jaarsveld, C. H., Llewellyn, C. H., Johnson, L., \& Wardle, J. (2011). Prospective associations between appetitive traits and weight gain in infancy. American Journal of Clinical Nutrition, 94, 1562-1567.

Wardle, J., Carnell, S., Haworth, C. M., Farooqi, I. S., O’Rahilly, S., \& Plomin, R. (2008). Obesity associated genetic variation in FTO is associated with diminished satiety. Journal of Clinical Endocrinology, 93, 3640-3643.

World Health Organization (WHO). (2006). WHO Child Growth Standards: Length/height-for-age, weight-for-age, weight-for-length, weight-for-height and body mass index-for-age: methods and development. Retrieved from https://www.who.int/publications/i/item/924154693X

Woo Baidal, J. A., Locke, L. M., Cheng, E. R., Blake-Lamb, T. L., Perkins, M. E., \& Taveras, E. M. (2016). Risk factors for childhood obesity in the first 1,000 Days: A systematic review. American College of Preventive Medicine, 50, 761-779.

Xing, J., Chen, M., Wood, C. G., Lin, J., Spitz, M. R., Ma, J., ... Wu, X. (2008). Mitochondrial DNA content: Its genetic heritability and association with renal cell carcinoma. Journal of the National Cancer Institute, 100, 1104-1112.

Zhao, W., Zhai, Y., Hu, J., Wang, Z., Kong, L., \& Chen, C. (2008). Economic burden of obesity-related chronic diseases in Mainland China. Obesity Reviews, 9, 62-67.

Zhou, B., Gao, W., Lv, J., Yu, C., Wang, S., Liao, C., ... Wu, F. (2015). Genetic and environmental influences on obesity-related phenotypes in Chinese twins reared apart and together. Behavior Genetics, $45,427-437$. 


\section{Appendix}

Table A1. Overall status of BMI $\left(\mathrm{kg} / \mathrm{m}^{2}\right)$ and overweight/obesity of Shanghai twins of different ages and birth weights

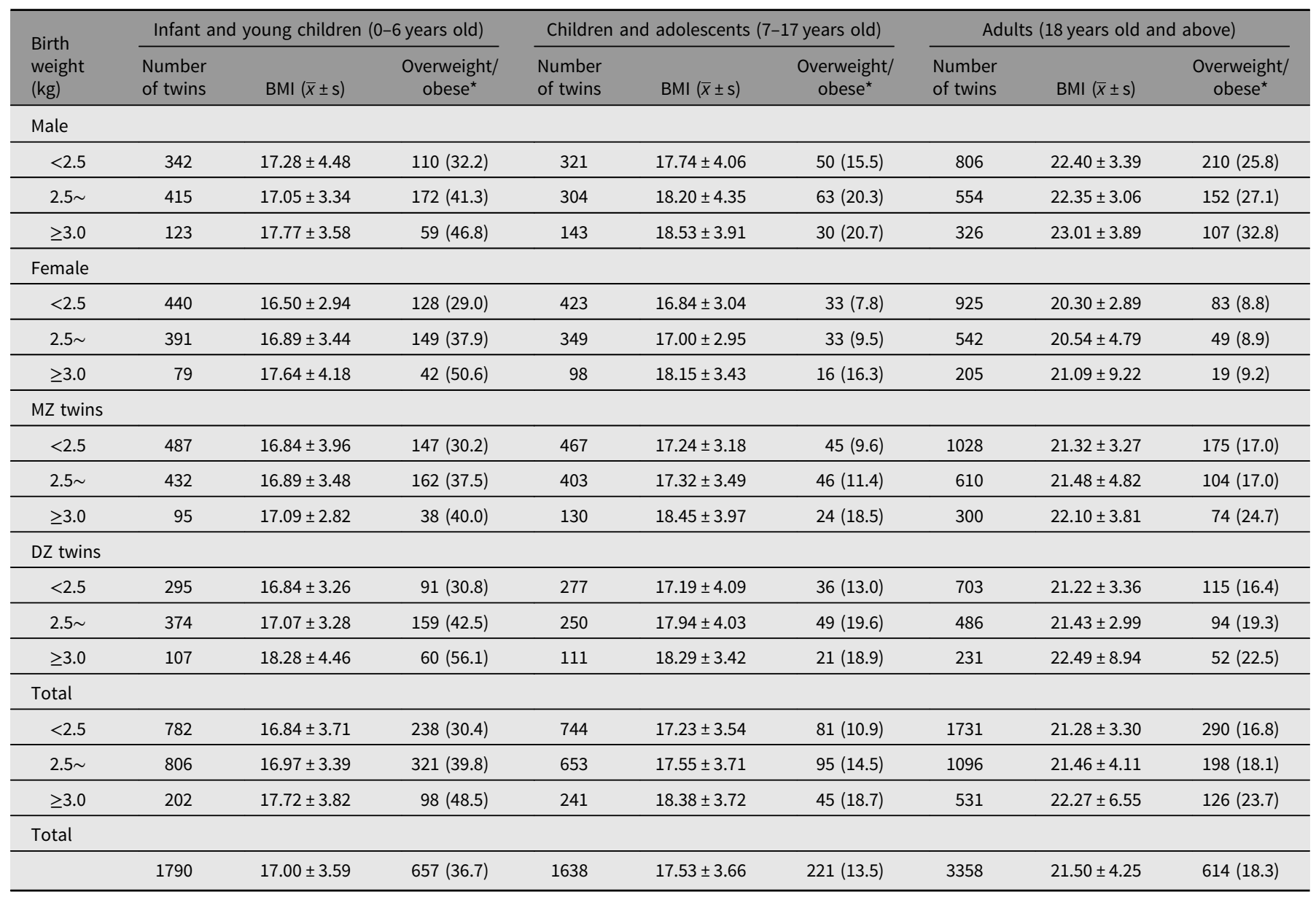

MZ, monozygotic; DZ, dizygotic.

${ }^{*}$ In the parenthesis indicates the standardized rate of overweight/obesity. 